\title{
Data Analysis on Student Proficiency Conjecture and Course Selection Assortment
}

\author{
A. ArokiarajJovith, D. Saveetha, Dheeraj Sharma \\ College of Engineering and Technology \\ SRM Institute of Science and Technology, Kattankulathur, Chennai, Tamil Nadu \\ arokiara@srmist.edu.in
}

\begin{abstract}
Conventional online instructive frameworks still have weaknesses when contrasted with a genuine study hall education, for example, absence of logical and versatile help, and absence of adaptable help of the introduction and input, absence of the agreeable help among understudies and frameworks. Likewise, they depend on the live information and anticipate the out comings dependent on that. This does exclude information of understudies in a foundation concentrating for some earlier years. This poses a problem for any learning and predictive algorithms to work on them. This work intends to assist the students in articulating their subject, club, project, internship, job preferences. In addition to student profiling, the venture additionally gives counsel to understudies with respect to how the profiles might be utilized to improve their scholastic and quantitative aptitude. In this regard, it is trusted that the profiles will give a valuable device to enable understudies to build up their employability. The profiling framework monitors the learning exercises and connection history of every individual understudy into the understudy profiling database model. In light of this model and along these lines the work demonstrates dynamic learning plans for individual understudies.Data analytic tools, classification techniques, and algorithms will be used to predict the outcomes of the student subject choices. Data (marks and interests) of the students will be classified into clusters upon which self-learning, predictive algorithms will be implemented to cater to students interests and needs. Regression techniques like map reduce will be used to segregate and classify data into definite datasets. It works on these four dimensions like input, comprehending, preparing and understanding. This paper gives the best way to use collaborative filtering strategies for understudy execution forecast. These strategies are frequently utilized in recommender frameworks like Netflix. The essential thought of such frameworks is to use the similitude of users dependent on their evaluations of the things in the system. We have chosen to utilize these procedures in the instructive condition to foresee understudy execution. We compute the comparability of understudies using their examination results, shown by the evaluations of their recently passed subjects.
\end{abstract}

Keywords:Conjecture, Selection, Assortment, Forecast

\section{Introduction}

To expand viability in conventional homeroom courses just as in Massive Open Online Courses (MOOCs), robotized frameworks supporting the educator are required. One vital issue is to naturally distinguish understudies that will do ineffectively in a course sufficiently early to have the capacity to take therapeutic activities. This report proposes a calculation that predicts the last grade of every understudy in a class. It issues a forecast for every understudy independently, when the normal precision of the expectation is adequate. The calculation realizes online what is the ideal expectation and time to issue a forecast dependent on previous history of understudies' execution in a course. We infer exhibit the execution of our calculation on a dataset got dependent on the execution of around 1000 college understudies who have taken a basic course of recent years. Utilizing information got from a pilot course, our system proposes that it is powerful to perform right on time in-class evaluations, for example, tests, which result in auspicious execution expectation for every understudy, in this manner empowering convenient mediations by the educator (at the understudy or class level) when essential.

As of now, school going understudies are taking more time to graduate than their parental ages. Improving the instructive quality via preparing better-readied understudies who can effectively graduate in an auspicious way is basic. Precisely foreseeing understudies' evaluations in future courses has pulled in much consideration as it can help distinguish in danger understudies early with the goal that customized criticism can be given to them on time by counsels. Earlier research on understudies' evaluation forecast incorporate shallow direct models; nonetheless, understudies' learning is a profoundly mind-boggling process that includes the gathering of learning over a succession of courses that cannot be adequately demonstrated by these direct models. Notwithstanding that, earlier methodologies centreon forecast exactness without thinking about forecast vulnerability, which is basic for prompting and basic leadership. In this work, we present collaborative filtering (CF) which is a courseexplicit model in light of the supposition that earlier courses can give understudies with information for future courses so evaluations of earlier courses can be utilized to foresee reviews in a future course. It disregards the worldly elements of understudies' information advancement. 


\section{Purpose of Statement}

To expand adequacy in customary study hall courses just as in Massive Open Online Courses (MOOCs), mechanized frameworks supporting the educator are required. One critical issue is to consequently distinguish understudies that are going to do ineffectively in a course sufficiently early to have the capacity to take healing activities. This report proposes a calculation that predicts the last evaluation of every understudy in a class. It issues a forecast for each understudy exclusively, when the normal precision of the expectation is adequate. The calculation realizes online what is the ideal expectation and time to issue a forecast dependent on previous history of understudies' execution in a course. We infer show the execution of our calculation on a dataset got dependent on the execution of roughly 1000 college understudies. Utilizing information acquired from a pilot course, our approach proposes that it is viable to perform right on time in-class evaluations, for example, tests, which result in convenient execution expectation for every understudy, along these lines empowering convenient intercessions by the teacher (at the understudy or class level) when important.

This report exhibits the procedure of understudy execution forecast by utilizing the Collaborative Filtering (CF). The advantage of this examination incorporates help teacher to distinguish understudy execution, customized exhorting, and understudy degree arranging. The CF system makes out of likeness estimation and expectation. In our trials, an earlier course bunching with heuristic information is received and distinctive methods of likeness estimation are looked at. The execution of every understudy has been anticipated by utilizing existing evaluations accessible around then.

A small part of the graduating understudies takes six years to wrap up four-year programs. The extra time required by understudies and low graduation rates has high human, money related and societal expenses with respect to workforce preparing and financial development. Absence of appropriate scholastic arrangement and arranging are a portion of the primary reasons that lead to understudy disappointment in advanced education. To improve standards for dependability and help understudies graduate in an opportune way, we expect to create investigation driven early cautioning and degree arranging frameworks that can distinguish in danger understudies; so that counsels can give them auspicious and customized input/guidance. Evaluation forecast is central for these frameworks.

\section{Literature Review}

Mack [1] builds up a framework for the undertaking of anticipating understudies' course reviews for succeeding enrolment term in an exceedingly antiquated college setting. Each term, understudies register in an exceedingly confined assortment of courses and procure reviews in the grading system of A-F for each course. The factorization machine (FM), equation proper for this errand, is utilized as the dynamic system and contrasted with a spread of various ways.

Zafar [2] demonstrated that in higher scholastic organizations, a few understudies are constrained to finish courses with no devoted help offered to understudies who need unique consideration inside the enlisted courses. AI methods is utilized for understudies' evaluations expectation in various courses. Such methods would encourage understudies to upgrade their performance, upheld predicted reviews and would alert teachers to spot such individuals who might potentially need assistance inside the courses. In this paper, in general utilises collaborative Filtering (CF), Matrix factorisation (MF), and Restricted Boltzmann Machines (RBM) procedures to methodically break down a certifiable data.

Agoritsa[3] demonstrated that the precise estimation of understudies' evaluations of upcoming subjects is critical because determination of upcoming semesters subjects and make customized framework to encourage effective, alsoopportune graduation. It also shows upcoming subjects forecasts procedure, models which can be explicit for every subject or understudy subject selected. The procedures set up the prognostic tuple of past subjects in a subject to subject premise and higher location issues identified with indiscriminately nature of the understudy subject recorded evaluation marks.

Bashir Khan [4] depicted that each organization round the globe keep up understudy result database that contain information with respect to understudy credits and in an all courses. It has fundamental concealed example/learning which might be revealed through information handling. A procedure used to isolate and is wide utilized for information investigation in this kind of database. The choice tree algorithmic program is connected to understudy past outcome learning to make a scenario inside the kind of choice tree. The procedure is used to foresee the understudy last grade. This will be valuable for instructor, understudy and their people to get a handle on before with respect to understudy last predicted evaluation and can change them to require attention.

Vamanan Ramesh [5] demonstrated that to recognize the variables affecting progress of researchers in conclusive exams and discover an appropriate information handling algorithmic program to foresee the evaluation of researchers along these lines and an alert cautioning to understudy's performance. In the paper, a review cum test philosophy was embraced to get data about their past grades and their folks' occupation. The 
acquired outcomes from theory testing uncovers that kind of school does not impact understudy's grades but guardians' occupation assumes a critical job in anticipating grades. This work can encourage the scholastic foundations to detect the researchers who are in peril and supply higher additional training for the underperforming scholars.

Mahesh Gadhavi [6] depicted in the paper discovered determinant for understudy performance in programming course. The extent of this paper was to deliver totally unique speculation to look out the connection between various factors. Creators recorded programming conduct of researchers, and afterward inspected the recorded data. In view of this data they prognosticated their abilities in essential programming subjects. They created one unique calculation called Warkin to foresee capability of an understudy in fundamental programming subjects. This model decreased endeavours in assessing understudy utilizing totally unique systems to anticipate the performance of an understudy in programming. Creator has arranged model to expand understudies' abilities in a few classes like participation in class, information of required courses. They also arranged the work of Artificial Neural Network and decision Tree for prescient demonstrating.

Murat Pojon[7] demonstrated that the point of the investigation was to coordinate totally extraordinary AI ways and include designing inside the understudy execution expectation. The expectation models were made utilizing the $\mathrm{R}$ language. It is a language conventionally utilized for AI applications. It has characteristically worked for the 3 different ways chose for this examination, that are linear regression, decision tree, and naive Bayes grouping. It moreover makes the required yield for assessing and refinement the consequences of expectations.

SergiRovira [8] delineated that a programmed device to process and break down the gathered yearly data information of the understudies might be remarkably useful for the procedure. In the paper, information driven framework, bolstered AI procedures are used for 2 totally extraordinary undertakings: 1) the primary forecast of understudies and 2) expectation of ensuing subject reviews for each understudy, still for customized subject proposals. An advance opt out expectation shows understudies who need assistance to them, guides will show considerable attention toward them and along these lines, increment their inspiration. Additionally, subjects' last marks forecasts and subject suggestions are supportive of supplying customized enrolment controlling and introduction.

RaheelaAsif [9] proposes that the Universities accumulate mammoth data ofunderstudies. The information preparing column makes it feasible to retrieve the useful information and notice data that bear the cost of imaginative ways that of supporting every instructor and understudies. This paper displays a contextual investigation on foreseeing their accomplishments at highest point in their college beginning period of the educational modules, in order to help colleges not exclusively to concentrate extra on splendid understudies anyway conjointly to at first decide understudies of meek instructive accomplishment and notice ways to help them. The information of 4 instructive companions including 347 student understudies are profound mined with entirely unexpected classifiers. The outcomes demonstrate that it's achievable to anticipate the graduation execution in fourth year at college utilizing exclusively high school marks and performance at first-and secondyear courses, with no financial or statistic alternatives, with a sensible precision. Moreover, courses that are markers of fundamentally shrewd or poor execution are known.

HashmiaHamsa's [10]work plans to build up understudy's performance expectation model, for understudies in various streams utilizing the characterization techniques. Columns of grades achieved throughout the semester were used. Grades characterised the participation grades, normal imprints got from exams. Confirmation marks for qualification understudies is that the sum total divided by number of tests acquired of tenth and twelfth test grades passage marks. [15] On account of qualification understudies, it incorporates semester grade checks and passageway grades. The final expectation model might be utilized to build up understudy's performance for each subject. In this manner, the teachers will characterize understudies related make an early move to upgrade their performance. Precise methodologies can be used for upgrading the marks achieved. Because of an advanced forecast, arrangements can be used, and improved outcomes can be normal in end of the year tests. Understudies can see their scholastic data and updates.

Amjad Abu Saa's [11] investigation paper to inquire about gathered understudies' information through a study, and supply characterizations dependent on the gathered learning to foresee and arrange understudies' performance in their subsequent semesters. [14] The goal of this examination is to recognize relations between understudies' social characteristics, and academic accompishments. This found information will encourage understudies yet as educators distinguishing underperformers early, and apply a ton of thoughtfulness regarding them in order to help them in their study strategy and get higher marks. Not only underperformers will benefit from this examination, yet good performers will benefit from the same.

A. T. M. ShakilAhamed's [12]paper meant to research financial and mental variables that have powerful effect on students' academic achievements.Insufficient instruction can be fixed by including basic approaches; finding these arrangements is the thing that review expects to do. Foreseeing the Higher Secondary evaluation can give an appropriate thought of what an understudy will most likely accomplish throughout everyday life. [13] Understudies experience immaturity before their HSC test and amid this stage, they are increasingly susceptible to their environment[16]. 


\section{Existing System}

With the emergence of recent academic technology like the world-Wide internet, it is a grave concern that numerous innovations throughout instructional history failed to last terribly long and resulted in bandwagons. Customary Web-based instructive frameworks still have a few inadequacies when contrasting and genuine classroom educating. Absence of logical and versatile help, absence of adaptable help of the introduction and input, absence of the cooperative help among understudies and frameworks.

In view of the dataset that gives data on understudy enrolment, scholastic performance, and socioeconomics are insufficient to comprehend the understudy's decisions. Not all parametric strategies that will in general return a not insignificant rundown of indicators, different techniques in studies propose that just a couple of factors are applicable, specifically, performance and discipline. Past research proposes that more established understudies incline toward well-known courses and along these lines a traditional approach in embracing new innovation is progressively reasonable to this group of students.

Studies found that more prospective students have stronger tendency to take online classes and new courses than older understudies. These discoveries can enable resources to organize assets for online course improvement and furthermore help institutional analysts and employees to comprehend their understudy better. Arrangements can be given to tweak instructional structure methodologies for explicit gatherings of an understudy. This will push understudies to know their range of abilities as well as help them apply same in different fields as well.

Lack of knowledge about courses; university or online (MOOC) available to students in various domains to select from apart from convention arbitrary choices posed at them. Lack of a robust interactive platform imparting information about various clubs and non-academic activities directly or indirectly boosting their academic abilities. No preferences available to students based on the courses availed in the past to streamline their growth. Little to no interaction between students and faculty members which hinders faculty members to assess student profile individually. No periodic counselling of students requiring emotional guidance.

Customary Web-based instructive frameworks still have a few inadequacies when contrasting and genuine classroom educating. Absence of logical and versatile help, adaptable help of the introduction and input, and cooperative help among understudies and frameworks. Students require help to select from courses which are unknown to them and may lead to choosing courses which they are not interested to select. Students do not only require attention in academic issues but also require mental support. Students having had backlog in past may require special attention and counselling to not have any more arrears.

\section{Proposed System}

The proposed system works in this way:

- Classification techniques: Used to segregate students according to their academic demographics and previous choices of courses and activities.

- Regression techniques: Help program learn about previous choices made and the performance based on different parameters like marks scored and attempts taken.

- Predictive algorithms: Based on the data availability of the students in the institution, current students may be helped to boost their marks in different fields.

- Online Platform: Descriptive information about courses (mandatory or elective) to be chosen, available internships and jobs in that field and periodic counselling for the same.

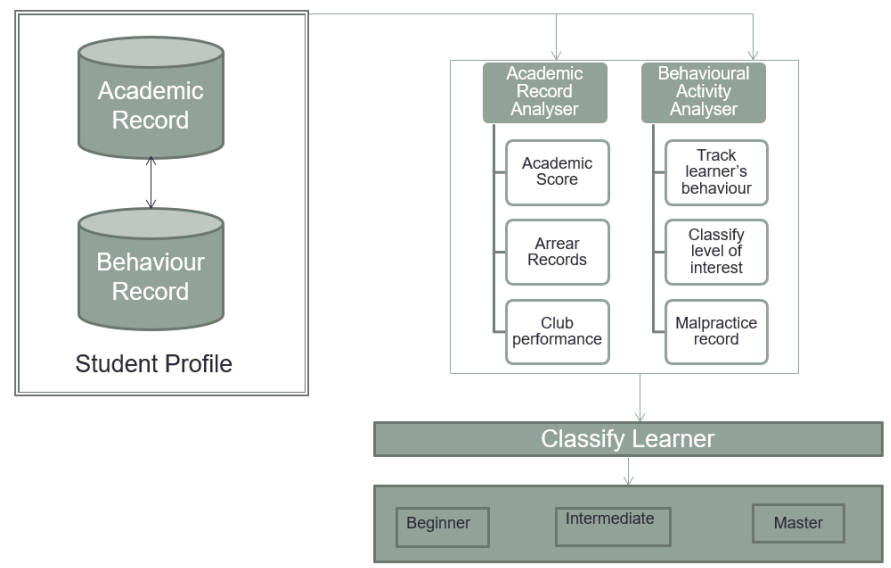

Figure 1:Proposed Architecture for Data Analysis 
Collaborative filtering (CF) - the CF calculations make expectations of GPA by distinguishing comparative understudies in the dataset. The algorithmic guideline estimates how comparable each understudy inside the data to the active understudy by plotting the comparability grid. It distinguishes the almost identical understudies by using $\mathrm{k}$ closest neighbours. Foreseeing the GPA of the course of the student by comparing the evaluation of Grade Point Average of that course taken by the similar comparative students. The conglomeration can be a straightforward mean or weighted normal by considering comparability between understudies.

CF has 2 types namely user-based and item-based CF. User based collaborative filtering tries to find $\mathrm{k}$ nearest users (students) who have scored similarly to past students. Although the name itself indicates marks scored in the subject to the closest $\mathrm{k}$ neighbours and predicts the score of the present student.

\subsection{Predictive Algorithm}

To address various issues of course selection, we propose a course-explicit system, which was appeared to be fruitful for precisely anticipating understudies' evaluations. Course-explicit techniques recognize a subset of earlier seminars on a course-by-course premise to foresee an understudy's evaluation in an objective course. They depend on the supposition that understudies aggregate essential information to take future courses by taking a succession of earlier courses. Our models are based upon this course-explicit system.

Education is in a change stage; new innovation considers customized instruction empowering understudies to learn all the more effectively and giving instructors the apparatuses to help each understudy exclusively if necessary, regardless of whether the class is substantial. Evaluaations should condense in a solitary number or letter how well an understudy had the capacity to comprehend and apply the information passed on in a course. Consequently, it is essential for understudies to get the vital help to pass and do well in a class. Be that as it may, with substantial class sizes at colleges and significantly bigger class sizes in Massive Open Online Courses (MOOCs) it has become outlandish for the teacher and educating collaborators to monitor the execution of every understudy exclusively.

From the viewpoint of instructive brain research, learning is influenced by both outer and interior factors, for example, inspiration, consider propensities, consideration and teacher instructional method, which bring about difficulties for evaluation forecast. These difficulties are further exacerbated by the way that learning is an impression of human insight which is an intricate procedure. These weak students may not be able to do catching complex collaborations basic understudy's learning. To better model understudies' learning procedure, we propose to utilize profound learning models. Another downside of conventional evaluation forecast techniques is that the anticipated evaluation is point estimation. To make educated choice dependent on the anticipated outcomes, we have to know whether the expectation framework is sure or not. In the event that the framework is sure enough about the expectations, we can depend on them and take comparing activities. Nonetheless, if the forecast isn't dependable, human counsellors ought to choose what to do.

\section{Implementation}

Our theory is that understudies' learning can be portrayed by courses that understudies go amid their interests. In view of this data we can choose understudies with comparative interests and learning and anticipate if a specific understudy has adequate abilities required for a specific course.

Cosine similarity (Center cosine similarity) is used to map the similar students (courses) based on their marks in courses chosen or their behavioural attitude.

$$
\begin{aligned}
& \operatorname{sim}(i, j)=\cos (\vec{i}, \vec{j})=\frac{\vec{i} \cdot \vec{j}}{\|\vec{i}\|_{2} *\|\vec{j}\|_{2}} \\
& \operatorname{sim}(i, j)=\frac{\sum_{u \in U}\left(R_{u, i}-\bar{R}_{u}\right)\left(R_{u, j}-\bar{R}_{u}\right)}{\sqrt{\sum_{u \in U}\left(R_{u, i}-\bar{R}_{u}\right)^{2}} \sqrt{\sum_{u \in U}\left(R_{u, j}-\bar{R}_{u}\right)^{2}}}
\end{aligned}
$$

Findksimilarusersfunction uses this method to return similarities and indices of k-nearest neighbours. Predictions are figured as weighted normal of deviations from neighbour's mean and adding it to active student's mean marks.

$$
p_{a, i}=\bar{r}_{a}+\frac{\sum_{u \in K}\left(r_{u, i}-\bar{r}_{u}\right) \times w_{a, u}}{\sum_{u \in K} w_{a, u}}
$$


The functions findksimilar terms adjust and predict item based adjust exploit adjusted cosine similarity to find $\mathrm{k}$ similar items and calculate the predicted marks. Once all the marks of subjects are predicted we recommend top $\mathrm{N}$ courses (electives), job preferences etc. to students.

At the end of the algorithm we are able to find subjects which are similar in due course and the prediction of scores in those subjects of a preferred student.

\section{Test}

As a general rule, understudies once in a while get suggestion concerning courses that they choose to take from understudies alike. That is, an ineffective way as sometimes an understudy doesn't feel great with the advices of a star understudy, as s/he typically believes that such an understudy has further aptitudes that s/he himself/herself does not have. Subsequently, such advices waould not make a difference to him. So also, scholastically great understudies in some cases don't take advices from ineffectively action understudies, as they may imagine that inadequately performing understudies may not take courses genuine or they might not have the acumen to examine legitimately. Subsequently, typically unwittingly, understudies converse with (or, even pick companions from) different understudies who are scholastically not altogether different from themselves. So as to reflect this social advancement in our technique, we ensure that future evaluation expectation for an understudy is performed just dependent on evaluations of different understudies with comparable scholastic performance. We use GPA as the intermediary marker of understudies' scholastic execution, and deny impressive GPA contrasts between understudies in the suggestion procedure.

M1, M2, M3... denote the subjects students take compulsory in their respective first and second semesters. M12, M13 and M14 are the subjects as electives to be chosen by student in the subsequent semester. The method described in this paper predicts marks scored by students in all the three present electives and recommends students to choose the subject or course(elective) which s/he scores the maximum marks in.

Table1: Suggestion Matrix

\begin{tabular}{|c|c|c|c|c|c|c|c|c|c|c|c|c|c|c|}
\hline ID & $\mathrm{m} 1=$ & $\mathrm{m} 2$ & $\mathrm{~m} 3=$ & $\mathrm{m} 4=$ & $\mathrm{m} 5 \div$ & $m 6=$ & $\mathrm{m} 7$ & $\mathrm{~m} 8$ ₹ & $\mathrm{m} 9=$ & $m 10=$ & $m 11$ & $\mathrm{~m} 12$ & $\mathrm{~m} 13$ & $\mathrm{~m} 14$ \\
\hline 1 & 70 & 68 & 77 & 56 & 61 & 65 & 77 & 64 & 60 & 74 & 54 & 69 & NA & NA \\
\hline 2 & 95 & 100 & 100 & 81 & 94 & 92 & 90 & 99 & 90 & 97 & 98 & NA. & NA & 85 \\
\hline 3 & 34 & 38 & 32 & 34 & 17 & 29 & 20 & 26 & 42 & 42 & 31 & NA & 25 & NA \\
\hline 4 & 54 & 71 & 62 & 72 & 42 & 58 & 68 & 75 & 62 & 49 & 70 & 49 & NA & NA \\
\hline 5 & 62 & 72 & 74 & 62 & 55 & 49 & 60 & 61 & 71 & 49 & 48 & NA & 68 & NA \\
\hline 6 & 43 & 52 & 54 & 51 & 33 & 56 & 52 & 43 & 43 & 33 & 58 & NA & NA & 43 \\
\hline 7 & 77 & 66 & 70 & 58 & 79 & 66 & 76 & 53 & 62 & 72 & 61 & NA & 81 & NA \\
\hline 8 & 66 & 64 & 58 & 43 & 68 & 45 & 44 & 63 & 59 & 44 & 60 & 50 & NA & NA \\
\hline 9 & 57 & 78 & 74 & 54 & 62 & 68 & 60 & 58 & 77 & 44 & 75 & $N A$ & 79 & NA \\
\hline 10 & 68 & 76 & 73 & 60 & 64 & 55 & 66 & 74 & 71 & 75 & 74 & 79 & $N A$ & $N A$ \\
\hline 11 & 83 & 94 & 90 & 95 & 79 & 69 & 87 & 74 & 69 & 93 & 94 & 74 & $N A$ & NA \\
\hline 12 & 58 & 55 & 54 & 52 & 48 & 43 & 53 & 60 & 47 & 42 & 41 & 52 & $N A$ & NA \\
\hline 13 & 42 & 36 & 34 & 20 & 22 & 27 & 30 & 22 & 37 & 25 & 32 & NA & $N A$ & 33 \\
\hline 14 & 51 & 56 & 51 & 61 & 49 & 58 & 60 & 43 & 44 & 50 & 59 & 57 & $N A$ & NA \\
\hline 15 & 81 & 99 & 93 & 73 & 97 & 91 & 84 & 90 & 87 & 97 & 86 & $N A$ & $N A$ & 92 \\
\hline 16 & 44 & 65 & 57 & 42 & 68 & 46 & 30 & 41 & 57 & 66 & 53 & 69 & $N A$ & NA \\
\hline 17 & 55 & 60 & 63 & 50 & 58 & 46 & 49 & 41 & 57 & 64 & 52 & $N A$ & 58 & NA \\
\hline
\end{tabular}


This does not only let the student to increase his/her marks in respective subjects but also make them aware if their interest lies in some particular domain.

\section{Results}

The same prediction is then used to alert faculties of the less scored domain for special attention. Behavioural data that can be mapped in the form of data input like quizzes, assignments and surprise tests Number Of Discussions, Hands Raised can be included in the student data to help with semester exams. Matter of concerns like mental health problems, depression, suicidal thoughts can be tackled using factors like number of arrears, malpractice (Semester back), low CGPA, lack of attendance and in case of no placement. Faculty free hours can be produced for students as such and upon elevation of mental health problems, the issue can be raised to the SRM DSA counsellors.

An item-to-item (subject to subject in our case) cosine similarity is performed in the implementation as the student-to-student similarity cosine will need a lot of attributes to be considered other than just marks scored in previous semesters. The characters needed other than just marks will be the student's behaviour in and out of class, interest in the subject, faculty teaching a specific subject and other intangible factors like economic and social environment around the student in that semester and any medical issues.

Testis play out a semester-based assessment. That is, we will in general re-enact the school lifetime of an understudy going from the essential semester. All the more explicitly, running from $\mathrm{N}=1$, we will in general use course marks from first $\mathrm{N}$-semesters to foresee the course reviews for the staying future semesters ( $\mathrm{N}$ is eight and no more, as there are 8 semesters in the current dataset). We rehash a similar procedure while increasing $\mathrm{N}$ by 1 in each analysis up until 7 which speaks to utilizing initial 7 semesters to foresee the course marks for the last semester.

Evaluating understudy marks in future courses might be priceless for three essential use cases: (I) giving direction to understudies so they can settle on educated decisions and arranging in regards to the elective courses likewise in light of the fact that a timely plan is required for the required courses, (ii) empowering teachers to tailor their class group and relate in regards to the dataset provided to them of the group of students about their learning capabilities, and (iii) serving to educators set up weak understudies before so they will orchestrate extra efforts for those understudies inside the sort of out-of-study hall exercises like, home exercises, peer-help, and so forth. In this paper, we propose an all-inclusive CF approach, and assess it on a genuine course grade dataset. We demonstrate that our methodology could appraise future understudy grades with improved exactness when contrasted with simple CF approach.

As a piece of our future work, we tend to endeavour to blend agreeable separating with group and arrangement approaches. All the more explicitly, we intend to distinguish understudy bunches with comparative scholarly accomplishment limits, and inside each gathering, apply versatile estimation strategies. We understand that this technique for classifying students will give students a ton of knowing choices during course registration period too.

\section{Conclusion}

Student modelling is a vital undertaking in instructive condition. We used CF strategies to foresee understudies' performance. $\mathrm{CF}$ is a typical method for creating customized suggestion. The fundamental thought of $\mathrm{CF}$ proposal approaches is to use data about the past conduct of students for anticipating the performance of the present students of the framework. We are keen on anticipating whether understudies will succeed or fail in a course that they need to join up with toward the start of a term. This implies we have no data about understudies' learning, abilities or excitement for a specific course but we can achieve a stable prediction. In this paper, we provide details regarding a plausibility to appraise understudy performance in a specific course dependent on information of understudy's recently passed courses. We use diverse CF strategies to evaluate our prediction. The solid expectation may assist instructors with identifying frail understudies so as to assist them with passing the course or to accomplish better evaluations. We can likewise prescribe acceptable deliberate courses to the understudies and caution them about troublesome obligatory courses that they need to pass.

In colleges, understudies pick courses subject to a combination of motivations. Some could pick a course in light of their interest in the lined material, while some others could take a course basically in light of the fact that $\mathrm{s} / \mathrm{he}$ appreciates the techniques the course faculty. Even more often, understudies will by and large settle on courses inside which they would like to get splendid assessments, at whatever point they are given plausibility in the structure elective courses. Hence, controlling understudies concerning their typical future course performance could enable them to shape illuminated judgments. Furthermore, such heading may be valuable for insightful 
advisors and instructors as well. Insightful guidance could endorse without question courses to their understudies in the midst of a customised way. Additionally, teachers may structure the content of the course as demonstrated by the insightful component of the present plan of understudies in the class at the soonest reference purpose of the semester, before it gets late inside the focal point of the semester. Moreover, potential fighting and low-performing understudies may be recognized at a starting time, and these understudies may be offered additional assistance as extra instructional exercise and practice sessions. Subsequently, giving customized suggests that of assessing future course assessments of students could hugely upgrade the preparation of students at schools. This will help student to choose subjects in subsequent semester wisely and also help him /her to go for internship in the same recommended field or domain.

\section{REFERENCE}

1. Mack Sweeney, Jaime Lester, HuzefaRangwala, "Next-term student grade prediction", 2015 IEEE International Conference on Big Data (Big Data), December 2015

2. ZafarIqbal, JunaidQadir, Adnan Noor Mian, Faisal Kamiran, "Machine Learning Based Student Grade Prediction: A Case Study", Published in ArXiv, 2017

3. AgoritsaPolyzou and George Karypis, "Grade Prediction with Course and Student Specific Models", International Journal of Data Science and Analytics, pp 159-171, 2016

4. Bashir Khan, Malik Sikander Hayat Khiyal and Muhammad DaudKhattak, "Final Grade Prediction of Secondary School Student Using Decision Tree”, International Journal of Computer Applications 115(21), pp 32-36, April 2015.

5. Vamanan Ramesh, P.Parkavi, K.Ramar, "Predicting Student Performance: A Statistical and Data Mining Approach", International Journal of Computer Applications (0975 - 8887), Vol. 63. No.8 , February 2013.

6. Mahesh Gadhavi, Dr. Chirag Patel, "Student Final Grade Prediction Based On Linear Regression", Indian Journal of Computer Science and Engineering, ISSN: 0976-5166, Vol.8, No.3, pp 274-279, July 2017.

7. Murat Pojon, "Using Machine Learning to Predict Student Performance", Faculty of Natural Sciences, University of Tampere, June 2017.

8. SergiRovira, EloiPuertas, and Laura Igual, "Data-driven system to predict academic grades and dropout", 10.1371/journal.pone.0171207

9. RaheelaAsif, AgatheMerceron, Mahmood K. Pathan, "Predicting Student Academic Performance at Degree Level A Case Study", International Journal of Intelligent Systems Technologies and Applications, pp 49-61, December 2014

10. HashmiaHamsa, Simi Indiradevi, Jubilant J.Kizhakkethottam, "Student Academic Performance Prediction Model Using Decision Tree and Fuzzy Genetic Algorithm", Procedia Technology, pp 326-332, December 2016.

11. Amjad Abu Saa, "Educational Data Mining \& Students' Performance Prediction", International Journal of Advanced Computer Science and Applications, May 2016.

12. A. T. M. ShakilAhamed, NavidTanzeemMahmood\&Rashedur M Rahman, "An intelligent system to predict academic performance based on different factors during adolescence", Journal of Information and Telecommunication, pp 155-175, April 2017.

13. S. T. Ahmed and K. K. Patil, "An investigative study on motifs extracted features on real time big-data signals," 2016 International Conference on Emerging Technological Trends (ICETT), Kollam, 2016, pp. 1-4, doi: 10.1109/ICETT.2016.7873721.

14. K. D. Singh and S. T. Ahmed, "Systematic Linear Word String Recognition and Evaluation Technique," 2020 International Conference on Communication and Signal Processing (ICCSP), Chennai, India, 2020, pp. 05450548, doi: 10.1109/ICCSP48568.2020.9182044

15. Gunashree, M., Ahmed, S. T., Sindhuja, M., Bhumika, P., Anusha, B., \&Ishwarya, B. (2020). A New Approach of Multilevel Unsupervised Clustering for Detecting Replication Level in Large Image Set. Procedia Computer Science, 171, 1624-1633. https://doi.org/10.1016/j.procs.2020.04.174

16. J. Dafni Rose*, K. Vijayakumar and S. Sakthivel, "Students' performance analysis system using cumulative predictor algorithm”, Int. J. Reasoning-based Intelligent Systems, Vol. 11, No. 2, 2019. 